\title{
COMPENSATION ALGORITHMS BASED ON THE P-Q AND CPC THEORIES FOR SWITCHING COMPENSATORS IN MICRO-GRIDS
}

\author{
L. F. C. Monteiro ${ }^{1}$, J. L. Afonso ${ }^{2}$, J. G. Pinto $^{2}$, E. H. Watanabe ${ }^{1}$, M. Aredes ${ }^{1}$, H. Akagi ${ }^{3}$ \\ 1 - COPPE - Electrical Engineering Program, Federal University of Rio de Janeiro, PO Box 68504, Rio de Janeiro, Brazil. \\ 2 - DEI - Industrial Electronics Department, University of Minho, Campus de Azurém - 4800-058, Guimarães, Portugal. \\ 3 - Department of Electrical and Electronic Engineering, Tokyo Institute of Technology, Tokyo 152-8550, Japan. \\ E-mails:1fcm@lemt.ufrj.br, jla@dei.uminho.pt, gpinto@dei.uminho.pt, watanabe@coe.ufrj.br, aredes@lemt.ufrj.br, akagi@titech.ac.jp
}

\begin{abstract}
The main objective of this paper is to compare the applicability and performance of a switching compensa-tor when it is controlled by algorithms derived from the $p q-$ Theory and from the Current's Physical Components Power Theory (CPC-Theory) considering a micro-grid application. Compensation characteristics derived from each one of these set of power definitions are highlighted, and simulation results of test cases are shown. Special attention is put on the oscillating instantaneous real power, as it may produce torque oscillations or frequency variations in weak systems (micro-grids) generators. The oscillating instantaneous real power, as defined in the pq-Theory, gives the amount of energy oscillating between the source and the load, and its compensation using a switching compensator must have an energy storage element to exchange it with the load. The energy storage element can be easily calculated with the pq-Theory.
\end{abstract}

Keywords - p-q Theory, Current's Physical Components Theory - CPC Theory, Power Quality, Switching Compensators, Micro-Grids.

\section{INTRODUCTION}

Compensation algorithms for switching compensators are one of the topics that have been exploited, exhaustively, by power-electronics engineers over the last almost 30 years. These compensation algorithms are derived from electricalpower theories that are defined in the frequency domain or in the time domain.

The conventional active $(\mathrm{P})$, reactive $(\mathrm{Q})$ and apparent powers (S), defined in the frequency domain [1]-[3], and several other power quality indices that are derived from them, only serve for off-line calculation and analysis of power quality issues. In general, power definitions in the time domain offer a more robust basis for the use in controllers for power electronic devices, because they are also valid during transients.

In 1983 Akagi, Kanazawa and Nabae proposed a timedomain power theory for the control of active filters connected to three-phase three-wire systems including some notes for four wires system [4]. Based on this theory, known today as $p-q$ Theory, other control strategies for active power line conditioners were derived in various publications [5][12], including its extension for the use in three-phase fourwire systems. A summary of these applications can be found

Manuscript received on $05 / 10 / 2009$. Revised on 18/11/2009. Accepted by recommendation of the Editor F.ernando L. M. Antunes. in $[5]$.

The $p$ - $q$ Theory is valid for any three-phase circuit conditions, and has the advantage of instantaneously separating homopolar (zero-sequence) from nonhomopolar (positiveand negative-sequence) components, which may be present in the instantaneous three-phase four-wire voltages and currents. Indeed, since their instantaneous powers are defined in the $\alpha-\beta-0$ reference frame, it is possible to extract, separately, the homopolar (zero-sequence) component. The $p-q$ Theory also allows a comprehensible explanation as to why imaginary power can be compensated without the need of energy storage elements [5][6]. Besides, it also allows determining the amount of energy that must be stored in a compensation device, in order to compensate oscillating powers that are exchanged between source and loads [7][8]. Furthermore, the $p-q$ Theory allows two compensation strategies: constant power at source and sinusoidal currents at source (using the fundamental positive-sequence components of voltage in the control algorithm) [13].

In the literature it can be found other power definitions defined in the time domain. The most important are the FBD (Fryze - Buchholz - Depenbrock) proposed by Depenbrock [14], the CPT (Conservative Power Theory) proposed by Tenti [15], and the CPC (Current's Physical Components) proposed by Czarnecki [16][17]. Also in the literature we can find $\mathrm{p}-\mathrm{q}$ Theory inspired control algorithms for switching compensators as, for example, the p-q-r Theory [18]-[20], which is also defined in the $\alpha-\beta-0$ reference frame. A comparison involving the $p-q-r$ and the $p-q$ Theories is provided in [20]. The control algorithm denominated as Synchronous Reference Frame (SRF) [21] also presents similar aspects related with the p-q-r and the p-q Theories. The SRF control algorithm is defined in the $\mathrm{d}-\mathrm{q}-0$ reference frame. All of these control algorithms can be applied to control switching compensators connected in three-phase systems, with or without neutral wire.

Control algorithms derived from the $p-q$ Theory have been widely applied to control switching compensators, and their control algorithms, are well established in the electrical engineering community involved in switching compensators design [5]. However, unfortunately, misinterpretations of the $p-q$ Theory still occur when it is considered as a power theory [16]. It occurs when the real and imaginary currents, derived from the $p-q$ Theory, are directly compared with the active and non-active currents defined by Fryze in 1932 [22]. As it is described in this paper, these current components can only be compared if certain constraints are respected.

In order to elucidate the aspects that still result in misin- 
terpretations of the $p-q$ Theory as a power theory, this paper exploits its power properties for three-phase electrical systems, with or without neutral wire. Moreover, it is also introduced a comparison involving control algorithms based on the $\mathrm{p}-\mathrm{q}$ and CPC theories for switching compensators connected in parallel with the electrical systems. In this paper, the CPC Theory was taken as reference for comparison, but any other or all of them could be taken as reference. The election of just one was due to the lack of space in this paper, and also to the fact that most of the conclusions may be extended to the other theories.

The focus of this comparison was supposed to be directed to the applications of power conditioners (switching compensators) in micro-grids, which generally are weak systems, and where active power oscillations may have to be compensated by using a short-term energy storage system. In fact, in a micro-grid, oscillating power may appear due to the oscillation in the load or oscillation in the renewable energy sources like wind power. Van der Hoven [23] reports the frequency variation range of the wind and in [24] it is shown that most micro-grids have torsional torque vibration that should be damped to avoid frequency variation. Suvire [25] analyzed and proposed solutions to overcome problems due to power variations given by wind generators connected to weak systems. However, the authors were not able to use the CPC Theory for this application as it is based on fundamental frequency, and the oscillating power with frequency components below the line frequency is not easily analyzed.

This paper is structured as follows. In section II it is described the instantaneous powers derived from the $p-q$ Theory, including their physical meaning in three-phase electrical systems. In sequence, in section III it is described the CPC (Current's Physical Components) power theory for three-phase electrical systems. In section IV it is introduced a comparison involving the CPC and p-q Theories based on a case example. Section V presents some simulations on the use of the $p-q$ Theory to compensate for power oscillations due to load and/or generation in a micro-grid. Finally, in section VI the major conclusions obtained through this work, and suggestions for further works are presented.

\section{POWER DEFINITIONS BASED ON THE $p-q$ THEORY}

The instantaneous real and imaginary power theory $(p-q$ Theory) is based on the Clarke transformation of three-phase voltages and currents into $\alpha-\beta-0$ coordinates. The Clarke transformation of three-phase voltages and currents are given by:

$$
\left[\begin{array}{l}
v_{\alpha} \\
v_{\beta} \\
v_{0}
\end{array}\right]=\sqrt{\frac{2}{3}}\left[\begin{array}{ccc}
1 & -\frac{1}{2} & -\frac{1}{2} \\
0 & \frac{\sqrt{3}}{2} & -\frac{\sqrt{3}}{2} \\
\frac{1}{\sqrt{2}} & \frac{1}{\sqrt{2}} & \frac{1}{\sqrt{2}}
\end{array}\right]\left[\begin{array}{l}
v_{a} \\
v_{b} \\
v_{c}
\end{array}\right]
$$

$$
\left[\begin{array}{l}
i_{\alpha} \\
i_{\beta} \\
i_{0}
\end{array}\right]=\sqrt{\frac{2}{3}}\left[\begin{array}{ccc}
1 & -\frac{1}{2} & -\frac{1}{2} \\
0 & \frac{\sqrt{3}}{2} & -\frac{\sqrt{3}}{2} \\
\frac{1}{\sqrt{2}} & \frac{1}{\sqrt{2}} & \frac{1}{\sqrt{2}}
\end{array}\right]\left[\begin{array}{l}
i_{a} \\
i_{b} \\
i_{c}
\end{array}\right]
$$

The instantaneous powers defined in the $\alpha-\beta-0$ reference frame are the real power $(p)$, the imaginary power $(q)$ and the zero-sequence power $\left(p_{0}\right)$ given by:

$$
\left\{\begin{array}{l}
p=v_{\alpha} \cdot i_{\alpha}+v_{\beta} \cdot i_{\beta}=\bar{p}+\tilde{p} \\
q=v_{\beta} \cdot i_{\alpha}-v_{\alpha} \cdot i_{\beta}=\bar{q}+\widetilde{q} \\
p_{0}=v_{0} \cdot i_{0}=\bar{p}_{0}+\tilde{p}_{0}
\end{array}\right.
$$

where, "-" represents the average and " $\sim$ " represents the oscillating components of each power. The average components can be extracted through low-pass filters, as it can be noted in several control algorithms for switching compensators [26]-[30]. It is worth to notice that, generally, the average components are calculated by considering the period of the line frequency as the time reference. However, as it was shown in [7][8], depending on the application the period for the calculation of the average value may be much higher than the period of the line frequency. In micro-grids applications this problem may occur.

In sequence, the physical meanings of the instantaneous powers defined in the $\alpha-\beta-0$ reference frame, including their average and oscillating components are described.

The instantaneous real power $(p)$ represents the energy, per time unity, that flows from the source to the load (or from the load to the source, if negative) through the threephase wires [5] [11]. The average component of the real power $(\bar{p})$, if positive, constitutes the energy, per time unity, that is transferred from the source to the load. The oscillating component $(\tilde{p})$ corresponds to the energy, per time unit, that is exchanged between the source and the load.

Conventionally, $\tilde{p}$ is calculated considering one line frequency period and the oscillating components are due to frequencies components higher than line frequency or due to the negative sequence component. In micro-grids where different kinds of low-inertia or non-dispatchable generators (wind generators) may be connected, $\widetilde{p}$ may appear due to harmonic frequencies, which can be dealt conventionally. However, frequencies lower than the line frequency may be present and the lack of inertia in the system may produce a oscillation in real power, which can be considered as $\widetilde{p}$. For example, if we consider a wind generator, as the wind speed varies along the time, the generated power may also vary along the time with a period given by the wind speed variation period (if it is periodic) or it may vary randomly. According to Van der Hoven [23] the harmonic spectrum of the wind speed contains frequency components in the range up to $0.017 \mathrm{~Hz}$ (period around 1 minute). This would force the appearance of very low frequency real and imaginary power oscillation in systems with wind generators.

In three-phase electrical circuits (with or without neutral wire) where voltages and currents are only comprised by 
their fundamental positive-sequence components, the energy transfer is unidirectional, normally from the source to the load. In this case, the instantaneous real power $(p)$ contains only its average component $(\bar{p})$. There are also others particular situations in which energy can present a unidirectional transfer from the source to the load as, for example, when voltages and currents present the same harmonic components and, moreover, present the same symmetrical components (positive, negative or zero components). In any other situations, where the voltages and currents are composed by distorted or unbalanced components, the instantaneous real power presents average and oscillating components.

The instantaneous zero-sequence power $\left(p_{0}\right)$ results from zero-sequence components of voltages and currents $\left(v_{0}\right.$ and $\left.i_{0}\right)$. It is important to comment that this power only exists in three-phase circuits with neutral wire. The average component $\left(\bar{p}_{0}\right)$ corresponds to the energy, per time unity, that flows from the source to the load using the neutral wire. The oscillating component $\left(\widetilde{p}_{0}\right)$ corresponds to the energy flow, per time unity, that is exchanged between source and load through the neutral wire. It is important to notice that the average component cannot exist without the presence of oscillating one [5].

The instantaneous three-phase active power $\left(p_{3}\right)$, determined in $a-b-c$ coordinates, and the instantaneous real power $(p)$ and instantaneous zero-sequence power $\left(p_{0}\right)$, determined in $\alpha-\beta-0$ coordinates, can be associated as follows:

$$
\begin{aligned}
& p_{3}=v_{a} i_{a}+v_{b} i_{b}+v_{c} i_{c}= \\
& =v_{\alpha} i_{\alpha}+v_{\beta} i_{\beta}+v_{0} i_{0}=p+p_{0}
\end{aligned}
$$

In an electrical system composed by voltages and currents with fundamental positive-sequence components only, it is possible to assure that the instantaneous three-phase active power $p_{3}$ and the instantaneous real power $p$ are equal, presenting only average component $(\bar{p})$. Moreover, as described in [5] [11] [12], in this condition is also possible to affirm that the conventional active power $(P)$ is equal to the instantaneous powers $p_{3}$ and $p$. In any other condition, the active power $(P)$ corresponds only to the average component of the instantaneous active power $\left(p_{3}\right)$.

The instantaneous imaginary power $(q)$ can be understood as responsible for the energy, per time unit, that is exchanged between the three-phase wires of the electrical system. Therefore, the power that flows in each phase and depends on $q$ does not contribute to the energy that flows from the source to the load or vice-versa. The instantaneous threephase reactive power $\left(q_{3}\right)$, determined in $a-b-c$ coordinates, and the imaginary power can be associated as follows:

$$
\begin{aligned}
& q_{3}=\left(v_{a}-v_{b}\right) i_{c}+\left(v_{b}-v_{c}\right) i_{a}+ \\
& +\left(v_{c}-v_{a}\right) i_{b}=\sqrt{3}\left(v_{\beta} i_{\alpha}-v_{\alpha} i_{\beta}\right)=\sqrt{3} q
\end{aligned}
$$

The instantaneous reactive power $\left(q_{3}\right)$ is similar to the conventional reactive power $(\mathrm{Q})$ only when the fundamental positive-sequence components of the voltages and currents are considered. When the currents or voltages present harmonic or unbalanced components, the instantaneous power $q_{3}$ contains average and oscillating components, which makes impossible to compare $q_{3}$ with Q.

Based on the aforementioned explanations involving the real, imaginary and zero-sequence powers, it is possible to conclude that:

- The total energy that flows per time unity, that is, the instantaneous three-phase active power is always equal to the sum of the real and zero-sequence powers;

- In three-phase circuits, with or without neutral wire, it is possible to affirm that the three-phase active power $\left(p_{3}\right)$ is equal to the conventional active power $(P)$, if the voltages and currents are only comprised by their fundamental positive-sequence components;

- The imaginary power is only derived from the nonhomopolar components of the voltages and currents. Moreover, there is a power in each phase that depends on the imaginary power, but their three-phase instantaneous sum is always equal to zero.

Fig. 1 shows the power exchange diagram in a three-phase four-wire system. In this figure, the power related to $q$ is shown circulating between the phases $a, b$ and $c$. The real power $p$ and $p_{0}$ represent the energy flow from system $A$ to system $B$ when they are positive. When they are negative they flow from system $B$ to system $A$.

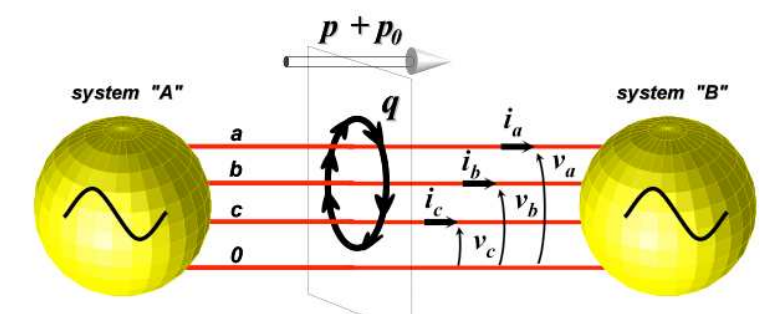

$p+p_{0}$ : instantaneous total energy flow per time unit;

$q$ : energy exchanged between the phases without transferring energy

Fig. 1 - Power exchange in a three-phase four-wire system.

Next, power definitions based on the CPC theory are presented. It is also described how the active, reactive, unbalanced and scattered currents are calculated. Such procedure is necessary to provide a reasonable comparison involving control algorithms derived from both $p-q$ and CPC power theories.

\section{POWER DEFINITIONS BASED ON THE CPC THEORY}

The Current's Physical Components (CPC) is a frequency-domain power theory applicable to three-phase three-wire systems (it does not apply to three-phase four-wire systems). In a generic three-phase three-wire system, where the voltages and currents may present harmonic components, the power properties are determined by four "independent features of the electrical system," according to [16][17]:

1) "permanent energy transmission and associated active power, $P$;

2) presence of reactive elements in the load and associated harmonic reactive power, $Q$; 
3) harmonic load unbalance that causes supply current asymmetry and associated harmonic unbalanced power, $D_{U}$;

4) scattered currents that cause an amount of energy, per time unit, that exchanges between source and load, and associated scattered power, $D_{S}$.

As described next in this section, each one of these powers is directly associated with current components extracted from the load current. Indeed, according to [31][34], the load current can be decomposed into four orthogonal components. These current components are denominated as the active current $\left(i_{A}\right)$, reactive current $\left(i_{R}\right)$, unbalanced current $\left(i_{U}\right)$, and scattered current $\left(i_{S}\right)$.

These current components are determined through minimization methods, based on the active and non-active currents defined by Fryze in 1932 [22]. The active component defined in the CPC theory totally corresponds to the active current defined by Fryze, whereas the sum of the remaining current components defined in the CPC theory corresponds to the non-active currents defined by Fryze.

Hereafter, it follows a mathematical methodology, according to the ones described in [32] and [33], to determine each one of the CPC current components and their associated powers. Initially, the Fast Fourier Transformer (FFT) algorithm is applied to the instantaneous values of the voltages $\left(v_{a}, v_{b}, v_{c}\right)$ and currents $\left(i_{a}, i_{b}, i_{c}\right)$, in order to obtain the complex RMS values (amplitude and phase values) for each component: $\dot{V}_{n a}, \dot{V}_{n b}, \dot{V}_{n c}$ and $\dot{I}_{n a}, \dot{I}_{n b}, \dot{I}_{n c}$, where the fundamental component is given for $(n=1)$ and the harmonic components are given for $n>1$. The complex power, of each $n$-component, is given by:

$$
\begin{aligned}
& \dot{S}_{n}=\dot{P}_{n}+j \dot{Q}_{n}=\dot{V}_{n a} \cdot \dot{I}_{n a}^{*}+\dot{V}_{n b} \cdot \dot{I}_{n b}^{*}+ \\
& +\dot{V}_{n c} \cdot \dot{I}_{n c}^{*}
\end{aligned}
$$

Once determined the complex power, it is possible to calculate the equivalent conductance $\left(G_{e n}\right)$ and susceptance $\left(B_{e n}\right)$ for the fundamental and for each harmonic component.

$$
\begin{gathered}
G_{n e}=\frac{\operatorname{Re}\left\{\dot{S}_{n}\right\}}{\left\|u_{n}\right\|^{2}}=G_{n a}+G_{n b}+G_{n c}, \\
B_{n e}=-\frac{\operatorname{Im}\left\{\dot{S}_{n}\right\}}{\left\|u_{n}\right\|^{2}}=B_{n a}+B_{n b}+B_{n c},
\end{gathered}
$$

where,

$$
\left\|u_{n}\right\|^{2}=\sqrt{V_{n a}^{2}+V_{n b}^{2}+V_{n c}^{2}}
$$

The active and reactive components, of each $n$ component, can be directly calculated through $\left(G_{n e}\right)$ and $\left(B_{n e}\right)$, together with the complex voltages $\left(V_{n a}, V_{n b}, V_{n c}\right)$, as described as follows:

$$
\begin{aligned}
& i_{A n}=\left[\begin{array}{l}
i_{A n a} \\
i_{A n b} \\
i_{A n c}
\end{array}\right]=\sqrt{2}\left[\begin{array}{l}
G_{n e} V_{n a} \\
G_{n e} V_{n b} \\
G_{n e} V_{n c}
\end{array}\right] \operatorname{Re}\left(e^{j n \omega_{1} t}\right) ; \\
& i_{R n}=\left[\begin{array}{l}
i_{R n a} \\
i_{R n b} \\
i_{R n c}
\end{array}\right]=\sqrt{2}\left[\begin{array}{l}
j B_{n e} V_{n a} \\
j B_{n e} V_{n b} \\
j B_{n e} V_{n c}
\end{array}\right] \operatorname{Re}\left(e^{j n \omega_{1} t}\right)
\end{aligned}
$$

The unbalanced component of the load current, $i_{U n}$, is given by:

$$
\boldsymbol{i}_{U n}=\boldsymbol{i}_{n}-\left(\boldsymbol{i}_{A n}+\boldsymbol{i}_{R n}\right) \quad ;
$$

where, the total current, $i$, is given by:

$$
i=\sum_{n=1}^{k} i_{A n}+i_{R n}+i_{U n}
$$

The scattered current is extracted from the active component $\left(\boldsymbol{i}_{A n}\right)$, which methodology is described as follows:

$$
\begin{aligned}
& G_{e}=\frac{P}{\left\|u_{1}\right\|^{2}}=G_{1 a}+G_{1 b}+G_{l c} \\
& i_{A}=G_{e}\left\|u_{l}\right\| \\
& i_{S n}=\left(\sum_{n=1}^{k} i_{A n}\right)-i_{A}
\end{aligned}
$$

where,

$$
\begin{aligned}
& P=\operatorname{Re}\left(\dot{V}_{a} \dot{I}_{A a}^{*}+\dot{V}_{b} \dot{I}_{A b}^{*}+\dot{V}_{c} \dot{I}_{A c}^{*}\right) ; \\
& \left\|u_{l}\right\|^{2}=\sqrt{V_{l a}^{2}+V_{l b}^{2}+V_{l c}^{2}}
\end{aligned}
$$

As it can be observed in (12), the scattered current is equal to zero for $n=1$. It is important to comment that these current components are mutually orthogonal, since the scalar product involving any of two of these components is equal to zero. Further explanations involving this feature can be found in [32]. Hereafter, according to [32] [33], are described the power phenomena involving each one of these current components.

The active current $\left(i_{A}\right)$ is directly involved with the active power transmission, and it totally corresponds to the active current defined by Fryze [26]. Therefore, the active power $(P)$ presented in (13) is equal to the conventional active power defined in the frequency domain.

As it is described in [33] the scattered component $\left(i_{S}\right)$ appears in the load current if the equivalent conductance of the load $\left(G_{n e}\right)$ changes with the harmonic order, i.e., if they are scattered around the $G_{e}$ value. The RMS value of the scattered current is given by:

$$
\left\|i_{S}\right\|=\sqrt{\sum_{n=1}^{k}\left(G_{n e}-G_{e}\right)\left\|u_{n}\right\|^{2}}
$$

The reactive component $\left(i_{R n}\right)$ is related to the presence of the reactive power $Q$, which one comprehends not only the fundamental component $(n=1)$, but also all of the $n$ harmonic components. The RMS value of $i_{R n}$ is given by:

$$
\left\|i_{R}\right\|=\sqrt{\sum_{n=1}^{k} B_{n e}^{2}\left\|u_{n}\right\|^{2}}
$$

Finally, the unbalanced component $\left(i_{U}\right)$ is related to the load asymmetry, which increases the RMS value of the load current. The RMS value of $i_{U}$ is given by:

$$
\left\|i_{U}\right\|=\sqrt{\sum_{n=1}^{k}\left\|i_{R}\right\|^{2}-\left(G_{n e}+B_{n e}\right)\left\|u_{n}\right\|^{2}} .
$$

Multiplying the RMS values of these current components by $\|u\|$ results in the power equations described as follows: 


$$
\begin{aligned}
& Q=\left\|i_{R}\right\|\|u\| \\
& D_{U}=\left\|i_{U}\right\|\|u\| \\
& D_{S}=\left\|i_{S}\right\|\|u\|
\end{aligned}
$$

The RMS value of $\|u\|$ is given by:

$$
\|u\|=\sqrt{\sum_{n=1}^{k}\left\|u_{n}\right\|^{2}}
$$

Thus, it can be noted that the RMS value of $\|u\|$ is different from the one described in (8), since the RMS value calculated in (18) comprises the fundamental and all of the harmonic components that the voltages might have. Based on the aforementioned explanations involving the power components defined by the CPC theory, it is possible to conclude that:

- The active component of the load current represents the smallest supply current necessary to transfer the energy, per time unit, from the source to the load;

- The reactive power defined by CPC theory $(Q)$ corresponds to the conventional reactive power, if and only if the currents and voltages do not present harmonics or unbalanced components.

It can be noted that there is no direct relation involving the power components derived from $p-q$ and CPC theories. Furthermore, such comparison only can be done in threephase three-wire systems, since the CPC theory does not provide a current component derived from the zero-sequence component, and thus, it cannot be applied to three-phase four-wire systems. In [17] it is presented a comparison involving the power components derived from the $p-q$ and the CPC theories, in a three-phase three-wire system with currents composed by an unbalanced component. In this comparison, the voltages are only considered to be fundamental positive-sequence component.

\section{COMPARISONS INVOLVING THE $p-q$ AND CPC THEORIES BASED ON A CASE EXAMPLE}

In this section are presented mathematical methodologies, based on the $p q$ and CPC theories, to determine the current components from a case example. It is worth to notice that control algorithms, for switching compensators as example, can be easily derived from the mathematical methodologies that are introduced in this section. Moreover, it is possible to provide comparisons involving the current components that are determined by both theories.

The case example consists of a circuit with an unbalanced resistive load, which is used in [16]. This circuit is shown in Fig. 2 (a), and an equivalent circuit, with the same characteristics, is presented in Fig. 2 (b).

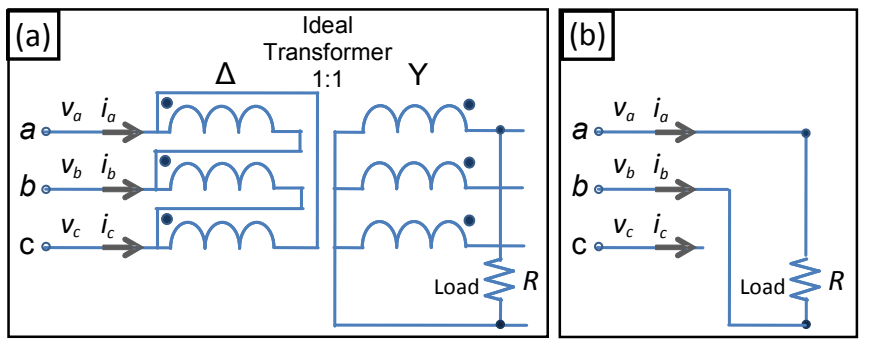

Fig. 2 - Example of an unbalanced resistive circuit: (a) Circuit like presented in [16]; (b) Equivalent circuit.

As described in [16] the resistance $R$ is equal to $2 \Omega$, and the phase voltages and currents on delta side (where the voltages and currents are indicated) are given by:

$$
\begin{array}{ll}
v_{a}=\sqrt{2} 120 \cos \left(\omega_{1} t\right) & V \\
v_{b}=\sqrt{2} 120 \cos \left(\omega_{1} t-120^{\circ}\right) & V \\
v_{c}=\sqrt{2} 120 \cos \left(\omega_{1} t+120^{\circ}\right) & V \\
i_{a}=\sqrt{2} 103.9 \cos \left(\omega_{1} t+30^{\circ}\right) & A \\
i_{b}=\sqrt{2} 103.9 \cos \left(\omega_{1} t-150^{\circ}\right) & A \\
i_{c}=0 & A
\end{array}
$$

Once the voltages and currents are decomposed into $\alpha$ and $\beta$ components, the real and imaginary powers are given by:

$$
\begin{aligned}
& p=\sqrt{3} V I\left(1+\cos \left(2 \omega_{1} t+60^{\circ}\right)=\right. \\
& =21.6\left(1+\cos \left(2 \omega_{1} t+60^{\circ}\right) \quad k W\right. \\
& q=\sqrt{3} V I \sin \left(2 \omega_{1} t+60^{\circ}\right)= \\
& =21.6 \sin \left(2 \omega_{1} t+60^{\circ}\right) \quad k v a i
\end{aligned}
$$

The $V$ and $I$ variables correspond to the RMS values of the phase-voltages and currents, respectively. Since the load is a resistive unbalanced one, the real power is composed by average and oscillating components and, the imaginary power is only given by an oscillating component.

Based on the calculated real and imaginary powers, together with the phase voltages transformed to $\alpha$ and $\beta$ components, it is possible to determine a set of currents corresponding to these powers. The currents derived from the average component of the real power are given by:

$$
\begin{aligned}
& i_{\alpha \bar{p}}=\frac{v_{\alpha}}{\left(v_{\alpha}^{2}+v_{\beta}^{2}\right)} \bar{p}=103.9 \cos \left(\omega_{1} t\right) A \\
& i_{\beta \bar{p}}=\frac{v_{\beta}}{\left(v_{\alpha}^{2}+v_{\beta}^{2}\right)} \bar{p}=103.9 \sin \left(\omega_{1} t\right) A
\end{aligned}
$$

Following the same methodology, it is possible to determine a set of currents derived from the oscillating components of the real and imaginary powers. These currents can be described as follows:

$$
\begin{aligned}
& i_{\alpha \widetilde{p}}=\frac{v_{a}}{\left(v_{a}^{2}+v_{b}^{2}\right)} \tilde{p}= \\
& =103.9 \cos \left(\omega_{1} t\right) \cos \left(2 \omega_{l} t+60^{\circ}\right) \quad A \\
& i_{\beta \widetilde{p}}=\frac{v_{b}}{\left(v_{a}^{2}+v_{b}^{2}\right)} \widetilde{p}= \\
& =103.9 \sin \left(\omega_{l} t\right) \cos \left(2 \omega_{1} t+60^{\circ}\right) \quad A
\end{aligned}
$$




$$
\begin{aligned}
& i_{\alpha \widetilde{q}}=\frac{v_{a}}{\left(v_{a}^{2}+v_{b}^{2}\right)} \widetilde{q}= \\
& =103.9 \sin \left(\omega_{1} t\right) \sin \left(2 \omega_{1} t+60^{\circ}\right) \quad A \\
& i_{\beta \widetilde{p}}=\frac{-v_{b}}{\left(v_{a}^{2}+v_{b}^{2}\right)} \widetilde{q}= \\
& =-103.9 \cos \left(\omega_{1} t\right) \sin \left(2 \omega_{1} t+60^{\circ}\right) A
\end{aligned}
$$

Through the inverse Clarke Transform it is possible to determine a set of three-phase currents, in $a-b-c$ reference frame, from the ones described in $\alpha-\beta-0$ components. This relation can be described as follows:

$$
\begin{aligned}
& i_{a}=\sqrt{\frac{2}{3}} i_{\alpha}+\frac{1}{\sqrt{3}} i_{0} \\
& i_{b}=-\frac{i_{\alpha}}{\sqrt{6}}+\frac{i_{\beta}}{\sqrt{2}}+\frac{1}{\sqrt{3}} i_{0} \\
& i_{c}=-\frac{i_{\alpha}}{\sqrt{6}}-\frac{i_{\beta}}{\sqrt{2}}+\frac{1}{\sqrt{3}} i_{0}
\end{aligned}
$$

The current components, in $a-b-c$ reference frame, derived from the real and imaginary current components given in (21) - (23) are determined as follows:

$$
\begin{aligned}
& i_{a \bar{p}}=\sqrt{\frac{2}{3}} i_{a \bar{p}}=84.8 \cos \left(\omega_{1} t\right) \quad A \\
& i_{b \bar{p}}=-\frac{i_{a \bar{p}}}{\sqrt{6}}+\frac{i_{b \bar{p}}}{\sqrt{2}}=84.8 \cos \left(\omega_{1} t-120^{\circ}\right) \mathrm{A} \\
& i_{c \bar{p}}=-\frac{i_{a \bar{p}}}{\sqrt{6}}-\frac{i_{b \bar{p}}}{\sqrt{2}}=84.8 \cos \left(\omega_{1} t+120^{\circ}\right) \mathrm{A} \\
& i_{a \widetilde{p}}=84.8 \cos \left(\omega_{1} t\right) \cos \left(2 \omega_{1} t+60^{\circ}\right) \quad A \\
& i_{b \widetilde{p}}=\cos \left(2 \omega_{l} t+60^{\circ}\right)\left(-42.4 \cos \left(\omega_{l} t\right)+\right. \\
& \left.+73.5 \sin \left(\omega_{l} t\right)\right) \quad A \\
& i_{\tilde{c} \widetilde{p}}=\cos \left(2 \omega_{1} t+60^{\circ}\right)\left(-42.4 \cos \left(\omega_{1} t\right)-\right. \\
& \left.-73.5 \sin \left(\omega_{1} t\right)\right) \\
& i_{a \widetilde{q}}=84.8 \sin \left(\omega_{l} t\right) \sin \left(2 \omega_{l} t+60^{\circ}\right) \quad A \\
& i_{b \widetilde{q}}=\sin \left(2 \omega_{1} t+60^{\circ}\right)\left(-42.4 \sin \left(\omega_{1} t\right)+\right. \\
& \left.-73.5 \cos \left(\omega_{1} t\right)\right) \quad A \\
& i_{c \widetilde{q}}=\sin \left(2 \omega_{1} t+60^{\circ}\right)\left(-42.4 \sin \left(\omega_{1} t\right)-\right. \\
& \left.-73.5 \cos \left(\omega_{l} t\right)\right) \\
& \text { A }
\end{aligned}
$$

It is worth to notice that when the current components $i_{a \widetilde{p}}, i_{b \widetilde{p}}, i_{c \widetilde{p}}$ and $i_{a \widetilde{q}}, i_{b \widetilde{q}}, i_{c \widetilde{q}}$ are summed, all the harmonic components contained in each one of these current components are canceled. These harmonic components are also denominated "hidden currents" [5][35]. The resulting currents are:

$$
\begin{aligned}
& i_{a \widetilde{p}}+i_{a \widetilde{q}}=84.8 \cos \left(\omega_{I} t+60^{\circ}\right) \quad A \\
& i_{b \widetilde{p}}+i_{b \widetilde{q}}=84.8 \cos \left(\omega_{I} t+180^{\circ}\right) A \\
& i_{c \widetilde{p}}+i_{c \widetilde{q}}=84.8 \cos \left(\omega_{1} t-60^{\circ}\right) \quad A
\end{aligned}
$$

The currents given in (28) can be considered as the unbalanced component of the currents $i_{a}, i_{b}, i_{c}$. In sequence, it is described a methodology to depict the system currents $\left(i_{a}, i_{b}, i_{c}\right)$ through the CPC theory. Since these currents do not present harmonic components, they can be decomposed into three active, reactive and unbalanced components described as follows:

$$
i_{n}=i_{A n}+i_{R n}+i_{U n}
$$

where $n=1$. The active, reactive and unbalanced components are given by:

$$
\begin{aligned}
& i_{A}=\sqrt{2} \operatorname{Re}\left\{G_{e} V e^{j \omega_{1} t}\right\} \\
& i_{R}=\sqrt{2} \operatorname{Re}\left\{j B_{e} V e^{j \omega_{1} t}\right\} \\
& i_{U}=i-\left(i_{A}+i_{R}\right)
\end{aligned}
$$

Based on Fig. 2, the conductance $\left(G_{e}\right)$ and the susceptance $\left(B_{e}\right)$ are determined through the equivalent admittance $\left(Y_{e}\right)$, on delta side of the transformer, described as follows:

$$
\begin{aligned}
& Y_{e}=G_{e}+j B_{e}=Y_{a b}+Y_{b c}+Y_{c a}= \\
& =(0.5+j 0) S
\end{aligned}
$$

In this particular case, it was simple to determine the equivalent admittance due to the load characteristic. However, this approach may be unfeasible when, for example, the load comprises non-linear components.

Once the equivalent admittance is determined, it is possible to calculate the active and unbalanced components of the system currents. These current components are given by:

$$
\begin{aligned}
& i_{A}=\left[\begin{array}{l}
i_{A a} \\
i_{A b} \\
i_{A c}
\end{array}\right]=\left[\begin{array}{c}
84.8 \cos \left(\omega_{1} t\right) \\
84.8 \cos \left(\omega_{1} t-120^{\circ}\right) \\
84.8 \cos \left(\omega_{I} t+120^{\circ}\right)
\end{array}\right] A . \\
& i_{U}=\left[\begin{array}{l}
i_{U a} \\
i_{U b} \\
i_{U c}
\end{array}\right]=\left[\begin{array}{c}
84.8 \cos \left(\omega_{1} t+60^{\circ}\right) \\
84.8 \cos \left(\omega_{1} t+180^{\circ}\right) \\
84.8 \cos \left(\omega_{1} t-60^{\circ}\right)
\end{array}\right] A .
\end{aligned}
$$

As expected, there are no reactive components since the equivalent susceptance $\left(B_{e}\right)$ is equal to zero. The active $(\mathrm{P})$ and unbalanced (D) powers are derived from the active and unbalanced current components, together with the phasevoltages, such that:

$$
\begin{aligned}
& P=\left\|i_{A}\right\|\|u\|=21.6 \mathrm{~kW} \\
& D=\left\|i_{U}\right\|\|u\|=21.6 \mathrm{kVA}
\end{aligned}
$$

Based on this case example, it is possible to make comparisons involving the currents components and powers derived from $p-q$ and CPC theories, such that:

$$
\begin{aligned}
& {\left[\begin{array}{l}
i_{a \bar{p}} \\
i_{b \bar{p}} \\
i_{c \bar{p}}
\end{array}\right]=\left[\begin{array}{l}
i_{A a} \\
i_{A b} \\
i_{A c}
\end{array}\right]} \\
& {\left[\begin{array}{l}
i_{a \widetilde{p}}+i_{a \widetilde{q}} \\
i_{b \widetilde{p}}+i_{b \widetilde{q}} \\
i_{c \widetilde{p}}+i_{c \widetilde{q}}
\end{array}\right]=\left[\begin{array}{c}
i_{U a} \\
i_{U b} \\
i_{U c}
\end{array}\right]} \\
& {\left[\begin{array}{c}
\bar{p} \\
\widetilde{p} \\
\widetilde{q}
\end{array}\right]=\left[\begin{array}{c}
P \\
D \cos \left(2 \omega_{1} t+60^{\circ}\right) \\
D \sin \left(2 \omega_{l} t+60^{\circ}\right)
\end{array}\right]}
\end{aligned}
$$

From the above comparison it is possible to conclude that, in general, there are good agreement between $p-q$ and CPC Theories. However, there are some important insights that the CPC Theory cannot answer. For instance, the unbalance 
power $\mathrm{D}$ comprises both the oscillating real $\tilde{p}$ and imaginary $\widetilde{q}$ powers. If the objective is to compensate all the harmonics in the circuit this is not a problem. However, if the objective is to compensate for only oscillating real power or oscillating imaginary power, the CPC Theory simply does not work. As it will be shown in the next section, in micro-grid applications it may be necessary to have compensation of the oscillating real power and for this it is essential to have this power separated from the imaginary power so one can easily calculate the size of the energy storing element.

Also, using the $p-q$ Theory it is possible to develop power conditioners to compensate for only imaginary power (reactive compensation, if only fundamental frequency is considered) or only oscillating real power. In fact, it can be used to control many different possible compensators. Therefore, it is not only a theory that allows the analysis of different compensators, but also it is also a very flexible theory.

\section{FREQUENCY CONTROL IN A MICRO-GRID}

To show the flexibility of the $p-q$ Theory some simulation result will be shown considering a micro-grid. Fig. 3 shows the simulated micro-grid with a combustion engine / synchronous generator as the dispatchable local power source, a wind generator, unbalanced nonlinear loads and a Shunt Power Compensator. It is supposed that the combustion engine / synchronous generator system is able to supply power to the loads, however, whenever possible, the wind generator is controlled to generate maximum power with the objective to save fuel. The load is unbalanced, nonlinear and variable. This is a hypothetical situation, however, highly probable to happen in an actual micro-grid. A situation where it is important to have a Shunt Power Compensator to avoid frequency variations will be presented.

Fig. 4 shows the instantaneous real power $p$ and the instantaneous imaginary power $q$, as well as the oscillating part of the instantaneous real power, $\tilde{p}$. Also, the time integral of $\widetilde{p}$ is included giving the amount of the oscillating energy in the system. To avoid frequency oscillation in the generator, the shunt compensator should deliver / absorb this energy. Knowing the peak value of this energy it is easy to calculate the size of the capacitor to be used in the DC side of the shunt compensator (in this example a capacitor was chosen as energy storing element), as shown in [7]. Based on this, a shunt compensator was designed to compensate for the oscillating instantaneous real power with a DC capacitor of $50 \mathrm{mF}$ and $860 \mathrm{~V}$. As this capacitor has to absorb energy from or supply energy to the load with a peak value of $650 \mathrm{~J}$, the capacitor voltage may vary $+/-160 \mathrm{~V}$. For larger values of stored energy another energy storing element may have to be used, like flywheel [25], batteries [36], or even SMES.

Fig. 5 shows the simulated voltage, current and frequency for the case that the Shunt Power Compensator is connected and compensating $\widetilde{p}$ and $q$. In this case, $\widetilde{p}$ was calculated as $\widetilde{p}=p-\bar{p}$ by using a moving average filter with a time

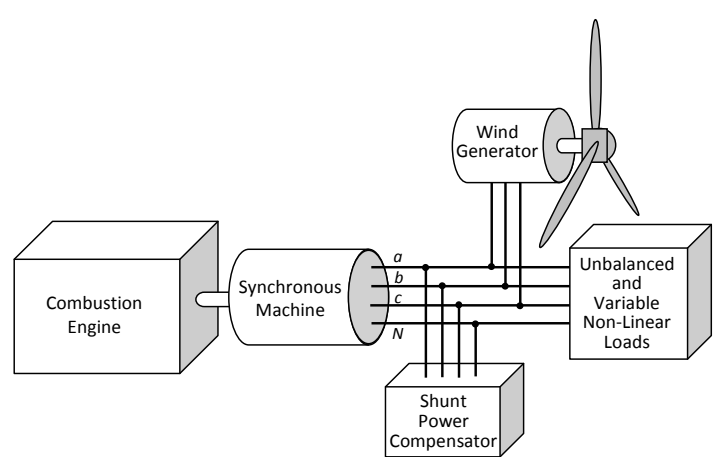

Fig. 3 - Simulated micro-grid with a combustion engine / generator, wind generator, unbalanced nonlinear loads and a Shunt Power Compensator.

window of 50 cycles for the calculation of the real average power $\bar{p}$. As it can seen in this figure, the voltage and current distortion has been greatly decreased and the frequency is now controlled. This simple simulation shows that a Shunt Power Compensator can be designed to compensate for oscillating power as in [7] with the difference that in this reference the power supply was running at constant frequency. In a micro-grid the inertia in the system may be too small to keep constant frequency. The compensated current is in phase with the voltage because all the imaginary power is being compensated.

Fig. 6 shows the imaginary power $q$, the real power $p$, the oscillating part of this real power $\tilde{p}$ and the integral of this power for the case shown in Fig. 5. The peak value of the integral of $\widetilde{p}$ is important for the calculation of the capacitor in the DC side of the compensator.

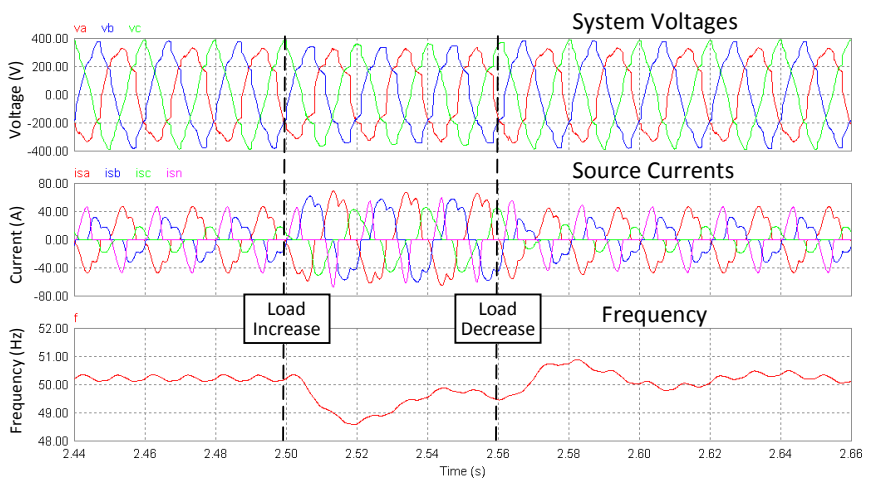

Fig. 4 - Voltage, current and frequency response for the system without Shunt Power Compensator.

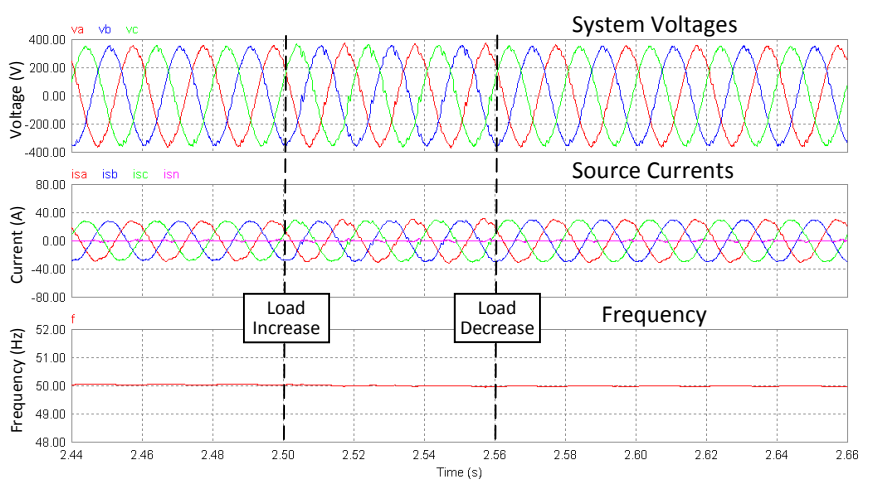

Fig. 5 - Voltage, current and frequency response for the system with Shunt Power Compensator. 


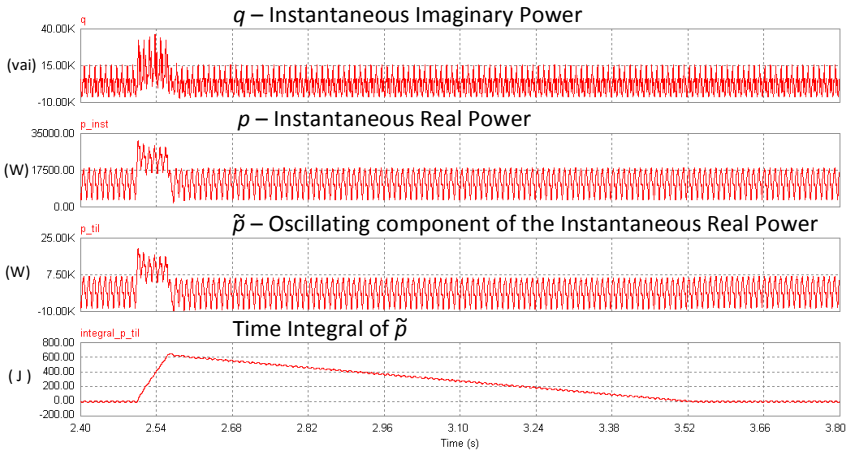

Fig. $6-q, p, \widetilde{p}$ and time integral of $\tilde{p}$ when load changes (see

Fig. 4 and Fig. 5), as calculated by the control system of the Shunt Power Compensator.

\section{CONCLUSIONS}

This paper presented a short summary of the $p-q$ and CPC Theories, including a comparison based on a simple example. As a result, it is possible to say that CPC Theory and $p-q$ Theory have many points in common. However, the first cannot be used in three-phase four-wire circuit, which is a limitation, as zero-sequence power cannot be even calculated. Also, CPC Theory cannot separate the effects of the oscillating real power from the oscillating imaginary power. This may be a hard limitation when analyzing a circuit where the instantaneous real power is oscillating and may cause torsional torque oscillation. This oscillation may lead to frequency variation, which is a problem in weak systems, and may be especially important in the case of future micro-grids, where it is expected to have a low inertia dispatchable power source and highly variable renewable energy sources, like wind or solar energy.

The use of the $p-q$ Theory allows the design of an active power compensator capable to eliminate oscillations in the instantaneous real power, avoiding variations of the electrical system frequency. Thus, the elimination of low frequency components in the instantaneous real power allows the mitigation of line frequency oscillations. Also, all the imaginary power and current unbalance can be compensated, guaranteeing maximum efficiency for the electrical system. The $p-q$ Theory also allows the calculation of the size of the energy storage element of a switching compensator, in a simple way, thus being an important tool in its design.

\section{REFERENCES}

[1] W. V. Lyon, "Reactive power and unbalanced circuits," Electr. World, vol. 75, no. 25, pp. 14171420, 1920.

[2] F. Buchholz, "Die Drehstrom-Scheinleistung bei ungleichmäßiger Belastung der drei Zweige," Licht Kraft, Zeitschrift elekt. Energie-Nutzung, no. 2, pp. 911, Jan. 1922.

[3] C. I. Budeanu, Puissances Reactives et Fictives. Bucharest, Romania: Instytut Romania de l'Energie, 1927, Pub. no. 2.
[4] H. Akagi, Y. Kanazawa, A. Nabae, "Generalized Theory of the Instantaneous Reactive Power in ThreePhase Circuits," in Proc. IPEC-Tokyo'93 Int. Conf. Power Electronics, pp. 1375-1386, Tokyo, 1983.

[5] H. Akagi, E. H. Watanabe, M. Aredes, Instantaneous Power Theory and Applications to Power Conditioning, New Jersey: IEEE Press / WileyInterscience, 2007, ISBN: 978-0-470-10761-4.

[6] H. Akagi, Y. Kanazawa, A. Nabae, "Instantaneous Reactive Power Compensator Comprising Switching Devices Without Energy Storage Components," IEEE Transactions on Industry Applications, vol. IA-20, no. 3, pp. 625-630, 1984.

[7] H. Akagi, A. Nabae and S. Atoh, "Control Strategy of Active Power Filter Using Multiple Voltage Source PWM Converters," IEEE Trans. Ind. Appl., vol. IA-22, no 3, 1986.

[8] E. H. Watanabe and M. Aredes, "Compensation of Non-Periodic Currents Using the Instantaneous Power Theory," IEEE PES Summer Meeting, Seattle, July 2000.

[9] E. H. Watanabe, R. M. Stephan, M. Aredes, "New Concepts of Instantaneous Active and Reactive Powers in Electrical Systems with Generic Loads," IEEE Transactions on Power Delivery, vol. 8, no. 2, pp. 697-703, April 1993.

[10] M. Aredes, E. H. Watanabe, "New Control Algorithms for Series and Shunt Three-Phase Four-Wire Active Power Filters," IEEE Transactions on Power Delivery, vol. 10, no. 3, pp. 1649-1656, July 1995.

[11] M. Aredes, "Active Power Line Conditioners," Ph.D. Thesis, Technische Universität Berlin, Berlin, 1996.

[12] J. L. Afonso, M. J. S. Freitas, J. S. Martins, "p-q Theory Power Components Calculations," 2003 IEEE International Symposium on Industrial Electronics, 2003, vol. 1, pp. 385-390, June 2003.

[13] João L. Afonso, Carlos Couto, Júlio Martins, "Active Filters with Control Based on the p-q Theory", IEEE Industrial Electronics Society Newsletter, vol. 47, $\mathrm{n}^{\mathrm{o}} 3$, Sept. 2000, pp. 510.

[14] M. Depenbrock, "The FBD-Method, a Generally Applicable Tool for Analysing Power Relations," IEEE Transactions on Power Systems, vol. 8, no. 2, pp. 381-387, May 1993.

[15] P. Tenti, E. Tedeschi, P. Mattavelli, “Cooperative Operation of Active Power Filters by Instantaneous Complex Power Control," 7th International Conference on Power Electronics and Drive Systems, 2007 (PEDS '07), pp. 555-561, November 2007.

[16] L. S. Czarnecki, "On some misinterpretations of the instantaneous reactive power $p-q$ theory," IEEE Transactions on Power Electronics, vol. 19, no. 3, pp. 828-836, May 2004.

[17] L. S. Czarnecki, "Instantaneous reactive power $p-q$ theory and power properties of three-phase systems," IEEE Transactions on Power Delivery, vol. 21, no. 1, pp. 362-367, January 2006. 
[18] H. S. Kim, H. Akagi, "The instantaneous power theory on the rotating 694 p-q-r reference frames," in Proc. IEEE/PEDS 1999 Conf., Hong Kong, pp. 422 - 427.

[19] M. Depenbrock, V. Staudt, H. Wrede, "Concerning instantaneous power compensation in three-phase systems by using $\mathrm{p}-\mathrm{q}-\mathrm{r}$ theory," IEEE Transactions on Power Electronics, vol. 19, no. 4, pp. 1151-1152, Jul. 2004.

[20] M. Aredes, H. Akagi, E. H. Watanabe, E. V. Salgado, L. F. Encarnação, "Comparisons Between the $p-q$ and $p-q-r$ Theories in Three-Phase Four-Wire Systems," IEEE Transactions on Power Electronics, paper accepted in October 6, 2008.

[21] R. I. Bojoi, G. Griva, V. Bostan, M. Guerreiro, F. Farina, F. Profumo, "Current Control Strategy for Power Conditioners Using Sinusoidal Signal Integrators in Synchronous Reference Frame," IEEE Transactions on Power Electronics, vol. 20, no. 6, pp. 1402-1412, November 2005.

[22] S. Fryze, "Wirk-, Blind- und Scheinleistung in elektrischen Stromkreisen mit nicht-sinusförmigem Verlauf von Strom und Spannung," ETZ-Arch. Elektrotech., vol. 53, pp. 596-599, 625-627, 700-702, 1932.

[23] I. Van der Hoven, "Power Spectrum of Horizontal Wind Speed in the Frequency Range from 0.0007 to 900 Cycles per Hour," Journal of Meteorology, vol. 14, pp. 160-164, April 1957.

[24] T. Goya et al., Torsional Torque Suppression of Decentralized Generators Based on $\mathrm{H} \infty$ Control Theory," International conference on Power System Transient (IPST'2009), Kyoto, 2-6 June 2009.

[25] G. O. Suvire, "Mitigation of Problems Produced by Wind Generators in Weak Systems," Ph.D. Thesis, San Juan National University, Argentina, 2009. (in Spanish).

[26] L. Malesani, L. Rosseto, P. Tenti, "Active Filter for Reactive Power and Harmonics Compensation," Power Electronics Specialist Conference, PESC '86, pp. $321-330$.

[27] Y. Xu, L. M. Tolbert, J. N. Chiasson, J. B. Campbell, F. Z. Peng, "A generalised instantaneous non-active power theory for STATCOM," IET Electr. Power Appl., 2007, 1, (6), pp. 853-861.

[28] Y. Xu, L. M. Tolbert, F. Z. Peng, J. N. Chiasson, J. Chen, "Compensation-based non-active power definition”, IEEE Power Electronics Letters, 2003, 1, (2), pp. 45-50.

[29] F. P. Marafão, S. M. Deckmann, J. A. Pomilio, R. Q. Machado, "Control Strategies to Improve Power Quality," COBEP 2001 - The 6th Brazilian Power Electronics Conference, Florianópolis, pp. 378-383.

[30] M. Aredes, L. F. C. Monteiro, "Compensation algorithms based on instantaneous powers defined in the phase mode and in the $\alpha \beta 0$ reference frame," COBEP 2003 - Brazilian Power Electronics Conference, Fortaleza, pp. 344-349.
[31] L. S. Czarnecki, “Current's Physical Components (CPC) in circuits with Nonsinusoidal voltages and currents. Part 2: Three-phase linear circuits," Electrical Power Quality and Utilization Journal, vol. X, no. 1, pp. 1 - 14, 2006.

[32] L. S. Czarnecki, "Orthogonal decomposition of the currents in a 3-phase nonlinear asymmetrical circuit with a nonsinusoidal voltage source," IEEE Transactions on Instrumentation and Measurement, vol. 37, no. 1, pp. 30 - 34, March 1988.

[33] L. S. Czarnecki, "Reactive and Unbalanced Currents Compensation in Three-Phase Asymmetrical Circuits under Nonsinusoidal Conditions," IEEE Transactions on Instrumentation and Measurement, vol. 38, no. 3, pp. 754 - 759, June 1989.

[34] L. S. Czarnecki, "Scattered and Reactive Current, Voltage, and Power in Circuits with Nonsinusoidal Waveforms and Their Compensation," IEEE Transactions on Instrumentation and Measurement, vol. 40, no. 3, pp. 563 - 567, June 1991.

[35] E.H. Watanabe, M. Aredes and H. Akagi, "The p-q Theory for Active Filter Control: Some Problems and Solutions", Revista Brasileira de Controle e Automação (SBA), Campinas/SP, Vol. 15, nº:01, pp. 78-84, Jan./Mar. 2004.

[36] H. Akagi and L. Maharjan, "A Battery Energy Storage System Based on a Multilevel Cascade PWM Converter," COBEP2009, Special Session, Bonito, September 2009.

[37] L. S. Czarnecki, "CPC power theory as control algorithm of switching compensators," Electrical Power Quality and Utilization, $9^{\text {th }}$ International Conference, Barcelona 9-11, October 2007.

\section{BIOGRAPHIES}

Luís Fernando Corrêa Monteiro was born in Rio de Janeiro, Brazil, on March 1975. He graduated in Electrical Engineering, from the Federal University of Rio de Janeiro (UFRJ) in 2002. In 2003 and 2008 received from the same university (UFRJ) the M.Sc. and Ph.D degrees, respectively. From 2006 to 2008 have developed researchers on his Ph.D. thesis at University of Minho (Portugal). His current research interests include custom power devices, multilevel converters and real-time control algorithms. Dr. Monteiro is a member of the Institute of Electrical Engineers and of the Brazilian Power Electronics Society.

João Luiz Afonso Associate Professor at the Department of Industrial Electronics of the University of Minho, Portugal, where he works since 1993. He finished his Engineering course and his M.Sc. at the Federal University of Rio de Janeiro, Brazil, respectively in 1986 and 1991. He concluded his $\mathrm{PhD}$ in Industrial Electronics at the University of Minho in 2000. He lectures the subjects of Electrical Machines, Complements of Power Electronics, Power Quality, Active Power Filters, and Renewable Energy. His researching activities are related with the Development of Active Power Filters, Power Quality Monitoring Systems, Power Electronics for Renewable Energy Sources and for 
Electric Vehicles, and with the realization of studies on Power Quality and Energy Efficiency. Dr. Afonso is a member of the Portuguese Engineering Council (Ordem dos Engenheiros), and of the IEEE.

José Gabriel Pinto J. G. Pinto received the degree in Industrial Electronics Engineering and the M.Sc. degree in Industrial Electronics from the Minho University, Guimarães, Portugal, in 2001 and 2004, respectively. From 2002 to 2006 worked as invited assistant at the Electrical Department of the Polytechnic Institute of Bragança. Since 2006, works as investigator at the Energy and Power Electronics group of the Industrial Electronics Department of the Minho University. Actually he is a PhD scholarship in Industrial Electronics Department of the Minho University.

Edson Hirokazu Watanabe was born in Rio de Janeiro, Brazil. He received the B.Sc. degree in electronic engineering and the M.Sc. degree in electrical engineering from the Federal University of Rio de Janeiro, Rio de Janeiro, in 1975 and 1976, respectively, and the Dr. Eng. degree from Tokyo Institute of Technology, Tokyo, Japan, in 1981. In 1981, he became an Associate Professor at COPPE, Federal University of Rio de Janeiro, where he became a Professor in 1993 and currently teaches power electronics. His current research interests include converters analysis, modeling and design, active filters, and flexible ac transmission system (FACTS) technologies. Dr. Watanabe is a member of the Institute of Electrical Engineers, Japan, the Brazilian Society for Automatic Control, and the Brazilian Power Electronics Society.

Maurício Aredes was born in 1961. He received the B.Sc. degree from Fluminense Federal University, Rio de Janeiro State, Niterói, Rio de Janeiro, Brazil, in 1984, the M.Sc. degree in electrical engineering from Federal University of Rio de Janeiro, Rio de Janeiro, Brazil, in 1991, and the Dr.-Ing. degree (magma cum laude) from Technische Universität Berlin, Berlin, Germany, in 1996. Currently, he is an Associate Professor with the Federal University of Rio de Janeiro, where he teaches Power Electronics. From 1985 to 1997, he was an R\&D Engineer, working on some projects and within Centro de Pesquisas de Energia Elétrica (CEPEL), Rio de Janeiro. His main research area includes HVDC and flexible ac transmission systems (FACTS) systems, active filters, custom power, and power quality issues. Dr. Aredes is a member of the Brazilian Society for Automatic Control and the Brazilian Power Electronics Society.

Hirofumi Akagi was born in Okayama, Japan, on August 19, 1951. He received the B.S. degree from Nagoya Institute of Technology, Nagoya, Japan, in 1974, and the M.S. and Ph.D. degrees from Tokyo Institute of Technology, Tokyo, Japan, in 1976 and 1979, respectively, all in electrical engineering. During 1979, he was with the Department of Electrical Engineering, Nagaoka University of Technology, as an Assistant and then Associate Professor. During 1987, he was a Visiting Scientist at Massachusetts Institute of Technology (MIT), Cambridge, for ten months. From 1991 to 1999, he was a Professor in the Department of Electrical Engineering, Okayama University, Okayama. From March to August 1996, he was a Visiting Professor at the University of Wisconsin, Madison, and then at MIT. Since January 2000, he has been a Professor in the Department of Electrical and Electronic Engineering, Tokyo Institute of Technology. He has made numerous presentations as a keynote or invited speaker internationally. He has authored or coauthored more than 70 IEEE journals and transactions papers, including two invited papers published in the PROCEEDINGS OF THE IEEE in 2001 and 2004. The total citation index of all his papers is more than 6000 as per Google Scholar. His current research interests include power conversion systems, ac motor drives, active and passive electromagnetic interference filters, high-frequency resonant inverters for induction heating and corona discharge treatment processes, and utility applications of power electronics such as active filters, selfcommutated back-to-back systems, and flexible ac transmission system devices.

Dr. Akagi was elected as a Distinguished Lecturer of the IEEE Power Electronics and the IEEE Industry Applications Societies for 1998-1999. He received two IEEE TRANSACTIONS ON INDUSTRY APPLICATIONS Prize Paper Awards in 1991 and 2004, two IEEE TRANSACTIONS ON POWER ELECTRONICS Prize Paper Awards in 1999 and 2003, nine IEEE Industry Applications Society Committee Prize Paper Awards, the IEEE William E. Newell Power Electronics Award in 2001, and the IEEE Industry Applications Society Outstanding Achievement Award in 2004. 